\title{
Increasing burden of osteoarthritis in Brazil from 2000 to 2017-- results from the Global Burden of Disease Study (GBD), 2017
}

\section{Aumento da carga de osteoartrite no Brasil de 2000 a 2017: resultados do Estudo Global de Carga de Doenças (GBD), 2017}

Fabricio Melo Bertolini ${ }^{1}$, (D)Amanda Aparecida Oliveira Leopoldino ${ }^{1}$, (D)uliano Vilela Dalia Mesquita ${ }^{2}$, (D) Ewerton Cousin ${ }^{3}$, (D) Valéria Maria de Azeredo Passos ${ }^{2}$

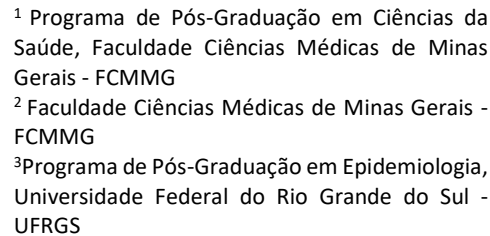

3Programa de Pós-Graduação em Epidemiologia Universidade Federal do Rio Grande do Sul UFRGS

\section{Corresponding}

Amanda Aparecida Oliveira Leopoldino

E-mail: aoliveiraleopoldino@gmail.com

Submitted: 6 May, 2020

Accepted: 5 Octuber, 2020

\section{Funding}

Bill \& Melinda Gates Foundation and Brazilian Ministry of Health and Brazilian National Health Fund (Fundo Nacional de Saúde) (25000192049 / 2014-14)

\section{How to cite}

Bertolini FM, Leopoldino AAO, Mesquita JVD, Cousin $E$, Passos VMA. Increasing burden of osteoarthritis in Brazil from 2000 to 2017results from the Global Burden of Disease Study (GBD), 2017. Acta Fisiatr. 2020;27(2):76- 81.

DOI: 10.11606/issn.2317-0190.v27i2a169404

\begin{abstract}
Worldwide, osteoarthritis (OA) is a leading cause of musculoskeletal disease and the second cause of work-related disability among adult men. There are few Brazilian population-based studies on $\mathrm{OA}$, none investigating the national burden. Objective: To investigate the burden of OA among Brazilian people (50+ years old), from 2000 to 2017. Method: Descriptive study on the estimates of OA obtained in collaboration with the study Global Burden of Disease 2017. Since $O A$ is not a cause of death, we described the prevalence and the years lived with disability (YLDs), representing the burden of disease (DALYs). We compare the metrics for Brazil with a developing country in Latin America (Chile) and two developed countries, with or without public health system (England and United States). Results: The number of cases in Brazil almost doubled from 2000 to 2017. All countries showed increasing age-standardized prevalence. Brazil presented the smallest rates and increase (9\%) in the period. OA raised from 14 th to the 12th cause of disability from 2000 to 2017 in those aged 50 to 69 and in 2017. The YLD rates of 100,000 inhabitants increased more than three times, in men and women, among those aged 50 to 54 years and in individuals over 80 years old. Aging was associated with a clear gradient increase in disability for both sexes and years analyzed. Conclusion: This first estimate of the burden of OA in Brazil highlight the importance of this cause of disability to health policymakers and call attention to the need for more research investments.
\end{abstract}

Keywords: Osteoarthritis, Global Burden of Disease, Prevalence

\section{RESUMO}

Em todo mundo, a osteoartrite (OA) é uma das principais causas de doenças osteomusculares e a segunda causa de incapacidade relacionada ao trabalho entre homens adultos. Existem poucos estudos brasileiros de base populacional, nenhum investigando a carga nacional. Objetivo: Investigar a carga de OA na população brasileira (50+ anos), de 2000 a 2017. Método: Estudo descritivo das estimativas de OA obtidas em colaboração com o estudo Global Burden of Disease 2017. Como a OA não é causa de óbito, descrevemos a prevalência e anos vividos com incapacidade (YLDs), representando a carga da doença (DALYs). Comparamos as métricas do Brasil com país em desenvolvimento da América Latina (Chile) e países desenvolvidos, com ou sem sistema de saúde pública (Inglaterra e Estados Unidos). Resultados: O número de casos no Brasil quase dobrou de 2000 para 2017. Todos os países apresentaram crescente prevalência padronizada por idade. O Brasil apresentou as menores taxas e aumento (9\%) no período. A OA foi da 14a para 12a causa de incapacidade entre 2000 e 2017, naqueles de 50 a 69 anos e em 2017. As taxas de YLD de 100.000 habitantes aumentaram mais de três vezes, em homens e mulheres, entre aqueles com 50 a 54 anos e em indivíduos acima de 80 anos. O envelhecimento associou-se a claro aumento da incapacidade para ambos os sexos e anos analisados. Conclusão: Essa primeira estimativa do ônus da OA no Brasil destaca a importância dessa causa de incapacidade para os formuladores de políticas de saúde e chama a atenção para a necessidade de mais investimentos em pesquisa.

Palavras-chave: Osteoartrite, Carga Global da Doença, Prevalência 


\section{INTRODUCTION}

Osteoarthritis (OA) is a leading cause of musculoskeletal diseases. Around $10 \%$ of the world's population with 60 or more years of age have clinical problems caused by $\mathrm{OA}^{1}{ }^{1}$ representing $20 \%$ of the causes of all chronic pain. ${ }^{2}$ Thanks to population aging, the prevalence of OA has been increasing rapidly. In 2050, more than $20 \%$ of the world's population is expected to be 60 or more years old, which represents around 130 million people with OA, with 40 million severely incapacitated by the disease. ${ }^{1}$

$\mathrm{OA}$ is the second leading cause of work-related disability among men over 50 years of age, after ischemic heart disease. Patients with OA generate about twice as many hospital expenses than other patients, ${ }^{3}$ and the economic burden of OA represents 1 to $2.5 \%$ of the Gross Domestic Product of Western nations. ${ }^{4}$

In Brazil, population-based prevalence studies are scarce and have diverse methodologies, which limits the comparison of the burden in the country.

Local studies have been published for more than 30 years. In 1996, a population-based survey in Bambuí (Minas Gerais State) showed $25.3 \%$ of medical diagnosis of rheumatism and $44.2 \%$ of self-reported chronic symptoms in hands and knees among the elderly (60+ years). ${ }^{5}$ In 2004 and 2009, two studies found similar OA prevalence using the Community Oriented Program for Control of Rheumatic Diseases (COPCORD) questionnaire. The studies showed prevalence rates of musculoskeletal symptoms of $30.9 \%$ among those aged $16+$ years in Montes Claros (Minas Gerais State) and 30.4\% among those with 18 to 65 years-old in Vitória (Espírito Santo State). The prevalence of $\mathrm{OA}$ was equal to $4.14 \%$ and $5.0 \%$, respectively. ${ }^{6,7}$

National studies are more recent. In 2003, the World Health Survey (WHS) showed an OA prevalence of $12.1 \%$ among men and $6.9 \%$ among women, upon a stratified random sample of 5,000 Brazilians over 18 years of age. ${ }^{8}$ In 2008, data from the Brazilian National Household Sample Survey (Pesquisa Nacional por Amostra de Domicílio) revealed that $19 \%$ of selfreported chronic diseases were due to musculoskeletal rheumatic diseases and spinal problems. Low back pain ranked second and arthritis/rheumatism ranked third among the leading causes of prevalent chronic diseases, after arterial hypertension. ${ }^{9}$

In 2013, the BRAZCO Study reported $26.9 \%$ of musculoskeletal symptoms unrelated to trauma in the seven days prior to interview among 5,000 people over 15 years of age in 16 capitals of the five Brazilian regions. ${ }^{10}$ The National Health Survey (Pesquisa Nacional de Saúde - PNS), carried out between 2013 and 2014, revealed a 21.6\% prevalence of musculoskeletal disease (by medical diagnosis, and selfreporting of "arthritis", "rheumatism", or "spine problems") in a representative sample of 60,202 people over 18 years of age in the five Brazilian regions. Women and the elderly were the most affected. ${ }^{11}$

In 2015 and 2016, the Brazilian Longitudinal Study of Aging (ELSI - Estudo Longitudinal da Saúde dos Idosos Brasileiros) showed $21 \%$ (Cl 19.4-22.7\%) of self-reported arthritis among 9,412 adults with 50 or more years-old from 70 cities in the five Brazilian regions. This prevalence was much higher than that found in the aforementioned PNS study (13.6\%, Cl 12.8-14.4), for the same age group. ${ }^{12}$

Due to population aging, it is important to assess the magnitude of the disability by OA in Brazil to support decisionmaking in public health, aimed at preventing or treating sequelae caused by this disease. Since 1990, the Global Burden of Disease Study (GBD) has been providing estimates of the burden of many diseases with a standardized methodology that allows comparison in time and among places. ${ }^{13}$

\section{OBJECTIVE}

This study aims to analyze the burden of OA among the 50 and over years-old Brazilian people, from 2000 to 2017, and compare with other countries: Chile, United States of America and England

\section{METHODS}

This study describes the GBD-2017 estimates of the burden of $O A$ derived from national data obtained and analyzed through the collaboration of a Brazilian network of researchers, the Brazil Ministry of Health and the Institute of Health Metrics and Evaluation (IHME) of the University of Washington. ${ }^{14}$

All estimates were showed by location, year, sex, and age group, and are available on the websites: http://www.healthdata.org/results/data-visualizations and http://ghdx.healthdata.org/gbd-results-tool ${ }^{13}$

Demographic data were provided by the Brazilian Institute of Geography and Statistics (Instituto Brasileiro de Geografia e Estatística - IBGE). ${ }^{15}$ Despite the availability of the data since 1990 , we decided to analyze the prevalence and metrics since 2000, excluding the period in which the national demographic data were less reliable.

OA was defined as a symptomatic disease with radiologic alteration with a Kellgren and Lawrence grade $(\mathrm{KL})$ equal to or greater than 2. As OA may affect any joint, the burden of OA was defined from the joints with higher prevalence, hips and knees, as defined by the codes 715 and M16 and M17 from the $9^{\text {th }}$ and $10^{\text {th }}$ Editions of the International Statistical Classification of Diseases and Related Health Problems (ICD), respectively. ${ }^{13,16}$

In Brazil, ICD-10 has been used since 1993, and it was the only source for case definition for the country in this study. The USA estimates used ICD-9.

The disability-adjusted life years (DALY) is representative of the global burden of disease, the sum of mortality (Years of Life lost-YLL) and morbidity (Years lived with disability-YLD) metrics. Since $O A$ is not a fatal condition and does not contribute to YLL, $100 \%$ of DALYs are due to YLDs. YLD/DALY to OA represents the years lived with disability across all sequel of the disease, defined as mild, moderate, and severe degrees. YLD is the product of the prevalence of each sequel multiplied its respective disability weight. ${ }^{13}$

YLDoA $=(0.023 \times$ mild sequel prevalence $)+(0.079 \times$ moderate sequel prevalence $)+(0.165 \times$ severe sequel prevalence) 
The disability weight of each sequel is a number from zero (absence of disease) to one (death), which represents the severity of health loss by OA. This value was defined from a standardized methodology based on population interviews with 60,890 adults (18+ years old), from several countries (Bangladesh, the USA, the Netherlands, Hungary, Indonesia, Italy, Peru, Sweden, and Tanzania).

The interviewed was asked to choose which sequel caused more limitation between two standardized descriptions of diseases, following a previously described methodology. ${ }^{13}$ The disability weights are $0.023,0.079$, and 0.165 for mild, moderate, and severe $\mathrm{OA}$, respectively. ${ }^{13}$

The GBD study has done three systematic reviews on the prevalence of OA worldwide. The GBD-2010 Study carried out a systematic review of articles published between 1980 and 2009 in the following platforms: MEDLINE, EMBASE, CINAHL, CAB Abstracts, WHO Library (WHOLIS), and OpenSIGLE. ${ }^{13,16}$

The following exclusion criteria were used: 1) subpopulations clearly non-representative of the population, 2) not a population-based study, 3) small size of sample (fewer than 150), 4) review instead of original studies, and 5) studies with hospital data. ${ }^{13}$

In 2017, data were updated with articles published between 2013 and 2017 in PubMed database. From the 1,864 articles on OA, after applied the exclusion criteria, 26 studies from 19 countries were used: Australia, Brazil, Canada, China, Ecuador, Egypt, India, Iran, the United Kingdom, France, Japan, the United States, Mongolia, Portugal, Spain, Mexico, Turkey, Venezuela, and Vietnam.

As only five knee OA and other five hip OA incidence studies were found, they were discarded due to low representativity. ${ }^{13}$

To identify Brazilian papers useful to GBD Study, we carried out a bibliographic search in the PubMed, SCIELO, and LILACS databases, using keywords in English and in Portuguese: osteoarthritis (osteoartrite), prevalence(prevalência), arthritis (artrite), and arthrosis (artrose), between the years of 2000 and 2017.

We found 22 Brazilian population-based articles with selfreported data that do not have fulfilled the inclusion criteria of the GBD study. The GBD-2017 study included two national studies to estimate the burden of $O A$ in Brazil: one based on the medical diagnosis of $\mathrm{OA}$ and the other based on the COPCORD questionnaire..$^{8,10}$

The Disease Modulation software, version 2.1 (DisMod-MR 2.1) was used to model YLD to each sex, age group, location, and year. It generates consistent estimates of prevalence for disease by using Bayesian models of meta-regression with covariates to adjust the estimates: data from studies that used self-reported OA diagnosis, diagnosis made by a health professional without radiological confirmation, or an asymptomatic OA radiography showing some alteration. ${ }^{13,16}$

To determine the magnitude of the burden of the disease Brazil, we compare its estimates to those of Chile, a Latin American country with a similar socioeconomic profile; the United States, a country with the greatest number of publications on OA; and England, a developed country with a public health system.

The GBD Brazil Study was approved by the Ethics and Research Committee (Project CAAE - 62803316.7.0000.5149) and was carried out exclusively with public secondary data without identifying the subjects. The ethics and research principles regarding human beings were observed, in conformity with the Resolution 466/2012 of the Brazilian National Health Council (Conselho Nacional de Saúde - CNS).

\section{RESULTS}

In Brazil, the number of cases of OA almost doubled during the study period, from 3,786,877.28 (95\% UI 3,399,387.05$4,236,252.84$ ) in 2000 to $7,248,483.50$ (95\% UI 6,501,005.83$8,108,721.70)$ in 2017 . This increase was also observed in the prevalence rates per 100,000 inhabitants, from $2,175.64$ (95\% UI 1,953.02-2,433.81) in 2000 to 3,422.12 (95\% UI 3,069.22$3,828.25)$ in 2017.

Although there existed overlap between the Uls, we notice a consistent trend of increasing in the age-standardized prevalence rates per 100,000 inhabitants, from 2,892.56 (95\% UI $2,597.72-3,239.89$ ) to $3,142.85$ (95\% UI 2,820.48-3,511.14) in 2000 and 2017, respectively.

In Figure 1, we can notice all countries presented increasing rates of age-standardized DALYs over time, for both sexes. The estimates were quite similar among the comparator countries, excluding the USA, with rates three to four times higher.
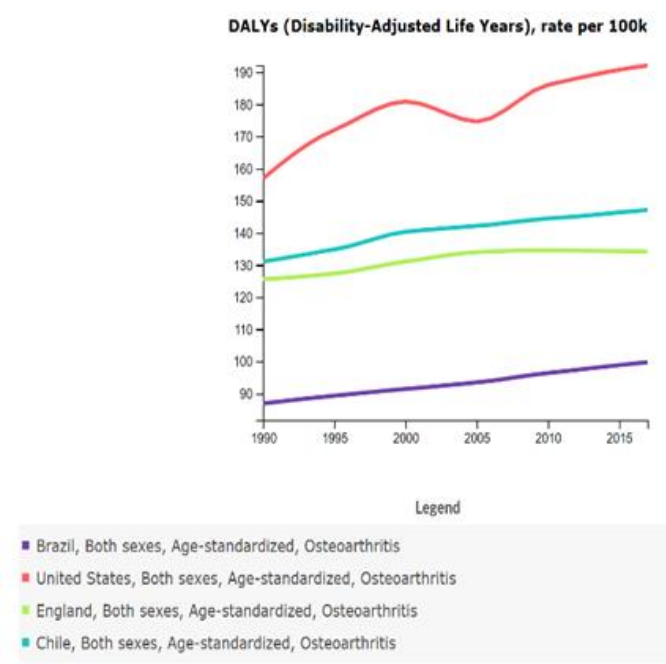

Figure 1. DALYS age-standardized over time

OA ranks among the 15 leading causes of disability in all the studied countries among those aged $50+$ years, being more relevant among the older population. We also noticed a trend of increasing relevance over time.

For example, from 2000 to 2017, OA in Brazil rose from 14 to $12^{\text {th }}$ position in the $50-69$ years of age group and from $13^{\text {th }}$ to $11^{\text {th }}$ position among those with $70+$ years. OA is more relevant in all comparator countries than in Brazil, even after considering age-standardized estimates (Table 1).

All countries presented a trend of annual increasing agestandardized prevalence, varying from $0.5-2.8 \%$, but the uncertainty interval's confluence precludes statistical significance. Once again Brazil presented the lowest OA prevalence rates for both sexes, whereas the USA had the highest ones. Estimates of Brazil are the only one without a sex difference in $O A$ prevalence, a higher prevalence among women was present among the other countries (Table 2). 
Table 1. Leading causes of YLD in Brazil, the USA, Chile and England in 2000 and 2017, among adults of 50-69 and 70+ years old

\begin{tabular}{|c|c|c|c|c|c|c|c|c|c|c|c|c|c|c|c|c|}
\hline & \multicolumn{16}{|c|}{ YLD ranking } \\
\hline & \multicolumn{8}{|c|}{$50-69$ years } & \multicolumn{8}{|c|}{$70+$ years } \\
\hline & \multicolumn{4}{|c|}{2010} & \multicolumn{4}{|c|}{2017} & \multicolumn{4}{|c|}{2010} & \multicolumn{4}{|c|}{2017} \\
\hline & USA & Bra & Chi & Eng & USA & Bra & Chi & Eng & USA & Bra & Chi & Eng & USA & Bra & Chi & Eng \\
\hline Low Back Pain & 1 & 1 & 1 & 1 & 1 & 1 & 1 & 1 & 2 & 2 & 2 & 1 & 3 & 2 & 1 & 1 \\
\hline Headache disorders & 6 & 4 & 7 & 3 & 5 & 3 & 6 & 3 & 15 & 14 & 17 & 15 & 14 & 14 & 16 & 13 \\
\hline Depressive disorders & 7 & 2 & 3 & 4 & 7 & 7 & 5 & 5 & 13 & 8 & 11 & 11 & 13 & 9 & 11 & 11 \\
\hline Anxiety disorders & 9 & 10 & 9 & 10 & 9 & 9 & 8 & 11 & 16 & 15 & 15 & 18 & 15 & 15 & 15 & 18 \\
\hline Other musculoskeletal & 5 & 9 & 4 & 6 & 6 & 8 & 4 & 8 & 10 & 18 & 12 & 19 & 9 & 19 & 13 & 16 \\
\hline Neck pain & 4 & 11 & 5 & 2 & 4 & 10 & 3 & 2 & 8 & 10 & 9 & 6 & 8 & 10 & 10 & 6 \\
\hline COPD & 3 & 8 & 11 & 5 & 3 & 11 & 12 & 6 & 3 & 7 & 6 & 3 & 1 & 7 & 6 & 3 \\
\hline Age-related hearing loss & 8 & 7 & 6 & 9 & 8 & 6 & 7 & 7 & 1 & 1 & 1 & 2 & 2 & 1 & 2 & 2 \\
\hline Diabetes & 2 & 3 & 2 & 8 & 2 & 2 & 2 & 4 & 5 & 5 & 3 & 5 & 4 & 5 & 3 & 4 \\
\hline Ostheoarthritis & 10 & 14 & 12 & 11 & 10 & 12 & 11 & 10 & 7 & 13 & 10 & 10 & 6 & 11 & 8 & 10 \\
\hline Other mental disorders & 17 & 20 & 15 & 20 & 18 & 19 & 16 & 20 & 25 & 21 & 22 & 25 & 25 & 21 & 23 & 25 \\
\hline Epilepsy & 34 & 24 & 29 & 33 & 34 & 24 & 28 & 33 & 35 & 22 & 27 & 34 & 30 & 22 & 26 & 36 \\
\hline $\begin{array}{l}\text { Blindness and vision } \\
\text { impairment }\end{array}$ & 31 & 5 & 10 & 13 & 29 & 4 & 10 & 13 & 18 & 3 & 4 & 8 & 18 & 3 & 4 & 8 \\
\hline
\end{tabular}

USA: United State of America; Bra: Brazil; Chil: Chile; Eng: England - Source: IHME, https://vizhub.healthdata.org/gbd-compare/

Table 2. Osteoarthritis prevalence, age-standardized in Brazil and compared countries between 2010 and 2017

\begin{tabular}{|c|c|c|c|c|c|c|}
\hline \multicolumn{7}{|c|}{ Prevalence by 100,000 inhabitants ( $95 \%$ UI) } \\
\hline & \multicolumn{3}{|c|}{ MEN } & \multicolumn{3}{|c|}{ WOMEN } \\
\hline & 2010 & 2017 & $\begin{array}{c}\Delta \% \text { aa* } \\
2010-2017\end{array}$ & 2010 & 2017 & $\begin{array}{c}\Delta \% \text { aa* } \\
2010-2017 \\
\end{array}$ \\
\hline Brazil & $3029.8(2729.0-3367.2)$ & $3138.7(2831.0-3497.8)$ & 2.77 & $3054.6(2729.1-3421.8)$ & $3145.7(2810.5-3525.1)$ & 2.69 \\
\hline Chile & $3670.8(3284.6-4101.0)$ & $3772.0(3371.5-4250.8)$ & 2.3 & $5289.3(4695.9-5958.6)$ & $5360.4(4767.4-6036.6)$ & 2.22 \\
\hline United States & $4961.1(4697.9-5259.5)$ & $5168.5(4845.3-5530.2)$ & 2.15 & $6728.9(6358.6-7188.8)$ & $6952.2(6486.2-7510.1)$ & 1.76 \\
\hline England & $3371.8(3038.1-3747.2)$ & $3417.3(3072.6-3796.2)$ & 1.05 & $5013.2(4480.5-5622.5)$ & $4984.6(4459.7-5596.4)$ & 0.5 \\
\hline
\end{tabular}

$\Delta \%$ a ${ }^{*}$ : percentage annual difference * UI- Uncertainty Intervals - Source: IHME, https://vizhub.healthdata.org/gbd-compare/

Table 3 shows the estimates by sex and age group in Brazil. For instance, in 2017, the YLD rates by 100,000 inhabitants increased more than three times, in men and women, respectively: from 204.0 (95\% II 100.2 - 407.3) and 202.7 (95\% II $100.2-405.4$ ) among those with 50 to 54 years-old to 660.1
(95\% UI 336.7-1,322.5), and 667.0 (95\% UI 340.0-1,324.8) in individuals over 80 years of age.

Despite the significaincrease, the large amplitude of all the confidence intervals is noteworthy, especially among the oldest individuals (Table 3).

Table 3. Years Lost due to disability by osteoarthritis in Brazil, by sex and age group, between 2000, 2010 and 2017

\begin{tabular}{|c|c|c|c|c|c|c|}
\hline \multicolumn{7}{|c|}{ Years lived with disability (YLD/DALY) per 100,000 inhabitants (95\% UI)* } \\
\hline \multirow[b]{2}{*}{ Age } & \multicolumn{3}{|c|}{ MEN } & \multicolumn{3}{|c|}{ WOMEN } \\
\hline & 2000 & 2010 & 2017 & 2000 & 2010 & 2017 \\
\hline $50-54$ & $183.6(91.6-365.7)$ & $196.4(98.8-394.2)$ & $204.0(100.2-407.3)$ & $187.15(93.1-377.4)$ & $196.2(96.8-394.0)$ & $202.7(100.2-405.4)$ \\
\hline $55-59$ & $258.25(129.4-511.4)$ & $276.7(137.5-549.0)$ & $287.5(143.3-570.3)$ & $262.6(130.5-522.1)$ & $276.2(136.5-550.7)$ & $285.5(141.6-563.9)$ \\
\hline $60-64$ & $338.1(166.7-674.89)$ & $361.4(175.5-724.5)$ & 375.7 (182.9 - 745.6) & $343.5(168.3-686.6)$ & $361.51(175.8$ - 731.0) & $373.9(182.3-750.3)$ \\
\hline $65-69$ & $414.9(203.8-821.3)$ & $441.0(215.6-869.5)$ & $457.8(223.5-898.8)$ & $422.2(206.4-843.5)$ & $442.8(219.3-864.9)$ & $457.9(227.2-910.3)$ \\
\hline $70-74$ & $485.7(241.9-973.1)$ & $513.3(257.8-1025.3)$ & $260.7(530.8$ - 1059.5) & $494.92(250.0-992.0)$ & $516.9(261.5-1033.4)$ & $534.4(265.9-1060.6)$ \\
\hline $75-79$ & $543.0(274.1-1100.7)$ & $572.9(288.8-1166.0)$ & $592.0(299.9-1184.4)$ & $553.0(278.6-1112.2)$ & $576.7(293.2$ - 1183.5) & $595.5(300.3-1198.1)$ \\
\hline+80 & $604.2(306.5$ - 1203.8) & $638.4(325.8-1269.6)$ & $660.1(336.7-1322.5)$ & $617.3(313.7-1225.5)$ & $645.2(329.3-1280.2)$ & $667.0(340.0-1324.8)$ \\
\hline
\end{tabular}

DALY-Disability adjusted years of life lost *UI-Uncertainty Intervals - Source: IHME, https://vizhub.healthdata.org/gbd-compare/

\section{DISCUSSION}

In this century, there is a consistent trend toward the increase of the burden of $O A$ as a cause of disability among adults and older adults in Brazil and all comparator countries. The most important predictor for the development of OA is aging, regardless of the studied association. ${ }^{17}$ In this sense, the profile of OA in Brazil mirrors the accelerated epidemiological and demographic transitions experienced by the country. In less than 40 years, there has been a rapid transition from the preponderance of infectious diseases to the greater relevance 
of chronic non-communicable diseases, which are typical of developed countries. The latter diseases are characterized by long duration and need for prolonged and costly health care, such as continuous medication or physiotherapy, and periodic exams. $^{18}$

In Brazil, disability by OA presented a clear increasing gradient with aging for both sexes. There are many theories for the increase of $O A$ prevalence with aging, but the most accepted one is that the etiology is multifactorial, ranging from a sedentary way of life to muscular weakness and oxidative damage and articular cartilage lesion. ${ }^{19}$

The population aging strengths the need to public health strategies. Longevity is a gain for civilization and the compression of morbidity is an important goal: elderlies should be healthy and independent as long as possible, succumbing to illness only at the end of their lives. ${ }^{20}$

Elderly care must take into account strategies to maintain physical and mental abilities that enable an independent and autonomous life. An elderly person who maintains his or her independence and self-determination should be consider healthy, even if he or she presents one or more chronic diseases. ${ }^{21}$

The Brazilian guidelines from the National Health Policy for the Elderly indicate the promotion of an appropriate diet, physical activity, and smoking cessation, among other measures, as well as the maintenance and improvement of functional capacity with the prevention, control, and rehabilitation of diseases. ${ }^{22}$

As behavioral risk factors such as obesity and physical inactivity are determinant for the burden of OA and of most chronic diseases, comprehensive policies should include mention to OA. ${ }^{4}$ Besides, it is essential to recommend specific ergonomic strategies to prevent overload of joints among construction workers, farmers, miners, professional athletes, military personnel, etc. This kind of repetitive trauma, over a decade or longer, increases the risk of articular degeneration. ${ }^{23}$

In this study, Brazil was the only country that did not presented a greater OA prevalence among women, probably reflecting the paucity of studies. The female sex is the second most important risk factor for OA worldwide. Women have twice the risk of developing bilateral knee $O A$ than men and have 2.6 times greater chance of developing hand OA. ${ }^{24}$

This difference is credited to anatomic factors, such as having a thinner articular cartilage layer, a three-degree-higher anatomic axial knee angle ( $Q$ angle), and a narrower distal femur than men. ${ }^{24}$ Menopause is another possible cause, many studies showing that articular cartilage is sensitive to estrogen deprivation. It has also been demonstrated that for each additional childbirth, women have a $2 \%$ increment in the risk for hip arthroplasty (95\% Cl 1-4) and of $8 \%$ (95\% Cl 6-10) for knee arthroplasty. ${ }^{4}$

This study has the merit of being the first study on the burden of OA in Brazil, part of a well-recognized worldwide study. Despite the few studies in Brazil, the GBD study advocates that health managers need timely, local, and valid estimates, whether or not there are recent data available about a disease, lesion, or risk for a certain population.

The lack of estimates does not mean there is no health problem. ${ }^{25}$ Health policymakers should not only focus on welldocumented issues, by use all documented or neglected problems, which may have higher relevance to the health improvement of a population. ${ }^{25}$

In order to increase the utility and reliability of the information, GBD studies always communicate the strength of the evidence, reporting $95 \% \mathrm{UI}$ for each quantity of interest. We can notice OA estimates in all countries still present large UI, more information been necessary.

The disability weight is a new paradigm in epidemiology, and allows knowledge on burden of non-fatal diseases. Since 1990, this construct is in progress: initially based on health specialists' panels, they evolved into measuring public opinion from different countries and schooling levels, which allows this measure to better represent the burden of the diseases. ${ }^{13}$ By combining the prevalence of the different sequelea of the disease, YLDs estimates further describe the burden of disability by OA than prevalence.

Nevertheless, the lack of data on OA in Brazil probably may explain its smallest estimates, as well as prevented a subnational analysis. There is a great heterogeneity among the studies, regarding to age groups, time, and place..$^{5,6,7,9,11,12}$

\section{CONCLUSION}

This first estimate of the burden of OA in Brazil highlight the increasing trend of $\mathrm{OA}$, associated with population aging, indicates Brazilian policymakers must address this disease along with the existing prevention strategies to other chronic diseases, especially those related to diet and physical activity. The paucity of studies may be responsible for the smallest estimates in Brazil, indicating the need for further researches.

\section{REFERENCE}

1. Wittenauer R, Smith L, Aden K. Osteoarthritis. In: Kaplan W, Wirtz VJ, Mantel-Teeuwisse A, (ed). Priority medicines for Europe and the World -- 2013 Update. Geneva: World Health Organization; 2013 [cited 2020 May 5]. Available from: https://www.who.int/medicines/areas/priority medicines/ba ck paper bp6/en/

2. Perrot S. Osteoarthritis pain: pathophysiology, diagnosis, and management. In: International Association for the Study of Pain. 2016 Global Year Against Pain in the Joints. Yokohama: IASP; 2016. [cited 2020 May 5]. Available from: https://s3.amazonaws.com/rdcms-

iasp/files/production/public/Content/ContentFolders/Glob alYearAgainstPain2/2016/FactSheets/English/13.\%200steo arthritis\%20Pain.pdf

3. Buckwalter JA, Saltzman C, Brown T. The impact of osteoarthritis: implications for research. Clin Orthop Relat Res. 2004;(427 Suppl):S6-15. Doi: https://doi.org/10.1097/01.blo.0000143938.30681.9d

4. O'Neill TW, McCabe PS, McBeth J. Update on the epidemiology, risk factors and disease outcomes of osteoarthritis. Best Pract Res Clin Rheumatol. 2018;32(2):312-326.

Doi:

https://doi.org/10.1016/j.berh.2018.10.007

5. Machado GPM, Barreto SM, Passos VMDA, Lima-Costa MFF. Projeto Bambuí: prevalência de sintomas articulares crônicos em idosos. Rev Assoc Med Bras. 2004;50(4):367$72 . \quad$ Doi: http://dx.doi.org/10.1590/S010442302004000400024 
6. Senna ER, De Barros AL, Silva EO, Costa IF, Pereira LV, Ciconelli RM, Ferraz MB. Prevalence of rheumatic diseases in Brazil: a study using the COPCORD approach. J Rheumatol. 2004;31(3):594-7.

7. Pereira AM, Valim V, Zandonade E, Ciconelli RM. Prevalence of musculoskeletal manifestations in the adult Brazilian population: a study using copcord questionnaires. Clin Exp Rheumatol. 2009;27(1):42-6.

8. World Health Organization. World Health Survey (WHS): report of Brazil. Geneva: WHO; 2003. [cited 2020 May 5]. Available from: https://www.who.int/healthinfo/survey/whsbra-brazil.pdf

9. Barros MB, Francisco PM, Zanchetta LM, César CL. Tendências das desigualdades sociais e demográficas na prevalência de doenças crônicas no Brasil, PNAD: 20032008. Cien Saude Colet. 2011;16(9):3755-68. Doi: http://dx.doi.org/10.1590/s1413-81232011001000012

10. Reis-Neto ET, Ferraz MB, Kowalski SC, Pinheiro GR, Sato EI. Prevalence of musculoskeletal symptoms in the five urban regions of Brazil-the Brazilian COPCORD study (BRAZCO). Clin Rheumatol. 2016;35(5):1217-23. Doi: http://dx.doi.org/10.1007/s10067-015-2963-5

11. Bezerra MAM, Hellwig $\mathrm{N}$, Pinheiro $\mathrm{G} R \mathrm{R}$, Lopes CS. Prevalence of chronic musculoskeletal conditions and associated factors in Brazilian adults - National Health Survey. BMC Public Health. 2018;18(1):287. Doi: http://dx.doi.org/10.1186/s12889-018-5192-4

12. Lima-Costa MF, Andrade FB, Roberto P, Souza B, Neri L, Aparecida $Y$, et al. Study design the Brazilian longitudinal study of aging (ELSI-Brazil): objectives and design. Am J Epidemiol. 2018;2010(16):1345-53. Doi: http://dx.doi.org/10.1093/aje/kwx387

13. GBD 2017 Disease and Injury Incidence and Prevalence Collaborators. Global, regional, and national incidence, prevalence, and years lived with disability for 354 diseases and injuries for 195 countries and territories, 1990-2017: a systematic analysis for the Global Burden of Disease Study 2017. Lancet. 2018;392(10159):1789-1858. Doi: https://doi.org/10.1016/S0140-6736(18)32279-7

14. Souza MFM, França EB, Cavalcante A. Burden of disease and health situation analysis: results of the Global Burden of Disease (GBD) Brazil network. Rev Bras Epidemiol. 2017;20Suppl 01(Suppl 01):1-3. Doi: https://doi.org/10.1590/1980-5497201700050001
15. Instituto Brasileiro de Geografia e Estatística [homepage na Internet]. Rio de Janeiro: IBGE; c2020 [citado 2020 Maio 5]. Disponivel em: https://www.ibge.gov.br

16. Cross M, Smith E, Hoy D, Nolte S, Ackerman I, Fransen M, et al. The global burden of hip and knee osteoarthritis: estimates from the global burden of disease 2010 study. Ann Rheum Dis. 2014;73(7):1323-30. Doi: https://doi.org/10.1136/annrheumdis-2013-204763

17. Palazzo C, Nguyen C, Lefevre-Colau MM, Rannou F, Poiraudeau S. Risk factors and burden of osteoarthritis. Ann Phys Rehabil Med. 2016;59(3):134-138. Doi: https://doi.org/10.1016/i.rehab.2016.01.006

18. Veras R. Envelhecimento populacional contemporâneo: demandas, desafios e inovações. Rev Saúde Pública. 2009;43(33):548-54. Doi: http://dx.doi.org/10.1590/S0034-89102009005000025

19. Litwic A, Edwards MH, Dennison EM, Cooper C. Epidemiology and burden of osteoarthritis. Br Med Bull. 2013;105:185-99.

http://dx.doi.org/10.1093/bmb/lds038

20. Veras R. Linha de cuidado para o idoso: detalhando o modelo. Rev Bras Geriatr Gerontol. 2016;19(6):887-905. Doi: https://doi.org/10.1590/1981-22562016019.160205

21. Brasil. Ministério da Saúde. Diretrizes para o cuidado das pessoas idosas no SUS: proposta de modelo de atenção integral. Brasília (DF): Ministério da Saúde; 2014. [citado 2020 Maio 5]. Disponível em: http://bvsms.saude.gov.br/bvs/publicacoes/diretrizes cui dado pessoa idosa sus.pdf

22. March LM, Bagga H. Epidemiology of osteoarthritis in Australia. Med J Aust. 2004;180(S5):S6-10. Doi https://doi.org/10.5694/j.1326-5377.2004.tb05906.x

23. Fries JF. Measuring and monitoring success in compressing morbidity. Ann Intern Med. 2003 Sep 2;139(5 Pt 2):455-9. Doi: $\quad$ https://doi.org/10.7326/0003-4819-139-5 part 2200309021-00015

24. Grazina R, Andrade R, Bastos R, Costa D, Pereira R, Marinhas J, Maestro A, Espregueira-Mendes J. Clinical Management in Early OA. Adv Exp Med Biol. 2018;1059:111-135. Doi: https://doi.org/10.1007/978-3-319-76735-2 5

25. Murray CIL, Lopez AD. Measuring global health: motivation and evolution of the Global Burden of Disease Study. Lancet. 2017;390(10100):1460-1464. Doi: https://doi.org/10.1016/S0140-6736(17)32367-X 